\title{
Psychometric Properties of Cognitive Assessment in Amyotrophic Lateral Sclerosis: A Systematic Review
}

This article was published in the following Dove Press journal: Patient Related Outcome Measures

\author{
Tina Taule \\ Margaret Søvik (D) ${ }^{2}$ \\ Regina Küfner Lein $\mathbb{1}^{3}$ \\ Eike Wehling ${ }^{4,5}$ \\ Jörg Aßmus $\mathbb{D}^{6}$ \\ Tiina Rekand $\left.{ }^{7}\right)^{7,8}$ \\ 'Department of Occupational Therapy, \\ Haukeland University Hospital (HUH), \\ Bergen, Norway; ${ }^{2}$ Department of Health \\ and Functioning, Western Norway \\ University of Applied Sciences, Bergen, \\ Norway; ${ }^{3}$ Medical Library, University of \\ Bergen (UiB), Bergen, Norway; \\ ${ }^{4}$ Department of Physical Medicine and \\ Rehabilitation, HUH, Bergen, Norway; \\ ${ }^{5}$ Department of Biological and Medical \\ Psychology, UiB, Bergen, Norway; \\ ${ }^{6}$ Centre for Clinical Research, HUH, \\ Bergen, Norway; ${ }^{7}$ Department of \\ Neurology, HUH, Bergen, Norway; \\ ${ }^{8}$ Institute of Neuroscience and \\ Physiology, Sahlgrenska Academy, \\ University of Gothenburg, Gothenburg, \\ Sweden
}

Correspondence: Tina Taule Email tina.taule@helse-bergen.no
Purpose: We aimed to list all tests used to assess cognitive change in patients with amyotrophic lateral sclerosis (ALS) and to provide a descriptive synthesis of the psychometric properties of tests that were evaluated in a population of ALS patients.

Materials and Methods: The protocol is registered in PROSPERO (ID: CRD42017055603). We systematically search for literature in 11 databases. Full-text articles, in any language, with original research were included. All included articles were scrutinised by two independent authors. Disagreement was resolved by consensus. The framework of Lezak informed conceptualises of the tests identified. To evaluate methodological quality, we used the Consensus-based Standards for the Selection of Health Measurement Instruments (COSMIN). Data were synthesised using criteria proposed by the Cochrane Back Review Group.

Results: Of 319 included articles, 46 articles reported information on the psychometric properties of cognitive tests used in patients with ALS. We found that the highest level of evidence was supported for the Reading the Mind in the Eye Test (RME), Addenbrooke's Cognitive Evaluation (ACE) and Frontal Assessment Battery (FAB). Moderate level of evidence was found for the screening tests; Edinburgh Cognitive and Behavioural ALS Screen (ECAS) and the Montreal Cognitive Assessment (MoCA).

Conclusion: The screening test, ECAS and the social cognition test, RME, may have some advantages over other tests that have been used for assessing cognitive change in ALS patients. Recommendations of ALS-specific tests with sound psychometric properties are urgently needed.

Keywords: ALS, cognition, feasibility, reliability, test, validity

\section{Introduction}

Insight about the cognitive changes that might occur in amyotrophic lateral sclerosis (ALS) has increased during the last decades. Such changes are now recognised as one of the integral features that characterizes this multisystem disease. ${ }^{1}$ Cognitive changes may influence ALS patient survival, ${ }^{2}$ caregiver burden, ${ }^{3}$ and affect decision-making processes regarding treatment. ${ }^{4}$ These findings stress the importance of accurately identifying those affected and detecting the extent of cognitive change. ${ }^{1,5}$ Early and repeated assessment may help healthcare professionals to better prepare families, enable individually tailored support, and provide timely opportunities for making essential decisions before impairment emerges. ${ }^{1,4}$

Recent studies show that the prevalence of cognitive changes in ALS varies between $30 \%$ and $62 \%{ }^{6,7}$ This wide range could be due to real differences in ALS 
patient characteristics (ie disease stage) or different tests used to assess cognitive changes. ${ }^{8-10}$ During the past years, more focus has been directed on cognitive assessment and Strong et al have recently published revised diagnostic criteria for ALS-specific cognitive impairment. ${ }^{1}$ To better define the extent and nature of changes, the authors differentiate between brief assessments and screening in clinical settings, assessment for prognostic stratifications in clinical trials and assessment focusing on research. A diagnosis of ALSspecific cognitive change depends on evidence of changes in executive function, including social cognition and/or language. ${ }^{1}$ Although controversy, evidence of memory dysfunction in patients with ALS are increasing. ${ }^{1,7}$ Changes in these cognitive functions may occur separately or in combinations with each other and should be assessed formally. ${ }^{1}$ As a minimum, Strong et al suggest assessment of Phonemic/ letter fluency early in the course of ALS, and that all patients undergo screening with the ALS Cognitive Behavioural Screen (ALS-CBS) or the Edinburgh Cognitive and Behavioural ALS Screen (ECAS). ${ }^{1,5,11}$ The necessity of further assessment may depend on whether changes in cognition are registered and/or the setting in which an assessment takes place. ${ }^{1}$ Moreover, the patient's physical disability, risk of exhaustion and possible practice effect should be taken into account. Further, Strong et al provide a list of tests, sensitive to ALS and recommended for evaluation of executive function, language and memory. According to the authors, extended assessment should include neuropsychologists or speech and language pathologists to support administration and interpretation of cognitive profiles and may thus not be feasible. ${ }^{1}$ Despite these efforts, not all instruments/ tests are available everywhere yet and more effort and knowledge are needed among both clinicians and researches. Better application of the Strong criteria, ${ }^{1}$ using tests covering a wide spectrum of cognitive symptoms may help to better understand ALS-specific cognitive changes. ${ }^{9}$

To aid healthcare professionals to make informed choices as they select tests capable of detecting ALSspecific cognitive changes, this review has the following objectives: (i) to list cognitive tests applied in ALSspecific healthcare (Phase I); (ii) to provide a descriptive synthesis of the psychometric properties of tests that were evaluated in a population of ALS patients (Phase II).

\section{Materials and Methods}

To ensure transparent reporting, we report our systematic review according to the Preferred Reporting Items for Systematic Review and Meta-analysis (PRISMA). ${ }^{12}$

\section{Protocol and Registration}

The protocol was registered with the International Prospective Register of Systematic Reviews (PROSPERO) before any study procedures were undertaken. The protocol was last updated on February 12, 2020, at the PROSPERO site, available from: http:/www.crd.york.ac.uk/PROSPERO/ display_record.php?ID=CRD42017055603. ${ }^{13}$

\section{Eligibility, Exclusion, and Inclusion Criteria}

Eligible for inclusion in this systematic review were research articles, published in full text and reporting on cognitive function in patients with ALS. Patients had to be diagnosed using recognised criteria common to ALSspecific healthcare. ${ }^{14-16}$ We excluded articles about studies that employed experimental cognitive paradigms and paradigms used in combination with PET/CT/FMRI when focused on neuroanatomical questions of ALS. We also excluded articles reporting on children or animal. Included in Phase I were all relevant articles, regardless of the publication date, language they were written in and published. Of these results, we selected in Phase II, only those articles reporting on psychometric properties of cognitive tests that were evaluated in patients with ALS.

\section{Information Sources}

Systematic online searches were carried out in the Cochrane Library, McMaster ${ }^{+}$, Epistemonikos, Medline, Embase, SveMed+, CINAHL, AMED, OT seeker, PEDro and PsycINFO. We also checked the reference lists of systematic reviews we identified for additional relevant articles.

\section{Search}

A trained librarian carried out database searches. Our first search was carried out in February 2017 in order to identify the cognitive tests used in ALS-specific health care (Phase I). Search terms covered subject headings and free text words for the following three concepts: ALS/MND, cognition and specific cognitive domains known in ALS, and assessment tools. A second search was performed in December 2019 in order to find validating studies of cognitive tests used in patients with ALS (Phase II). In this second search we added a forth concept; psychometrics, to the searches in the main medical databases (Medline, Embase, PsycINFO, CINAHL, Cochrane Library), according to the search strategy filters developed by the Hedges Team for detecting clinical prediction studies. ${ }^{17,18}$ See Supplementary material 1 for the search 
strings and the exact terms that we used for Medline and Embase in the first and the second search.

\section{Study Selection and Data Collection Process}

In Phase I, all references from the first search were screened. In Phase II in order to find validating studies, included references from Phase I and new references from the second search were screened. Two of the authors independently screened all references and extracted the data. Consensus for inclusion was reached by discussion among the authors. For articles written in languages others than English, we consulted professional colleagues who are knowledgeable about health terminology in those languages. For eight articles, we contacted the authors for additional clarifying information.

\section{Data Items}

In Phase I, a neuropsychologist listed all the tests with sufficient supporting references used in the selected studies and classified them according to the cognitive domains they address; attention, concept formation and reasoning, construction and motor performance, executive functioning, learning and memory, perception, social cognition, verbal functions and language skills. This procedure was mainly based on well-established work in the field of neuropsychology $y^{19,20}$ as well as on test manuals or aim (s) of the studies of the included articles. In this evaluation, we were aware that the classification could to some extent vary, depending on the perspective of the investigators. Batteries, rating scales, inventories and screening tests were categorised separately when all subtests were applied. Since several articles, however, reported on just a few subtests from the complete test battery, and names used seemed not always identical with the original ones, names of the batteries were assigned to the above domain categories. When a complete battery was used, it was assigned separately. ${ }^{20}$

In Phase II, we extracted various characteristics of the included articles and published information on each identified test regarding psychometric properties. We were particularly interested in studies that evaluated the feasibility, internal consistency, reliability (test-retest reliability, interrater reliability), content validity, construct validity (structural validity and hypotheses testing), criterion validity and responsiveness of tests, as most of these evaluation parameters are specifically addressed in the Consensus-based Standards for the Selection of Health Status Measurement Instruments (COSMIN). ${ }^{21}$ In Table 1, definitions and explanations of the above-mentioned psychometric properties (except feasibility) are presented together with recommendations of preferred statistical methods and minimum sample size to include in analyses.

\section{Assessment of Study Quality (Risk of Bias)}

In Phase II, we evaluated the risk of bias and methodological quality of the studies in the included articles. We used the four steps of the COSMIN checklist. ${ }^{21}$ Only the standards corresponding to the psychometric property of interest were used and accompanied by specific explanations and instructions given in the COSMIN checklist. ${ }^{21}$ As feasibility is not part of the COSMIN checklist, we did not evaluate the methodological quality of studies that assessed the feasibility of the tests they used.

\section{Level and Synthesis of Evidence}

For tests identified in Phase II, we first calculated a quality score (excellent, good, fair, or poor) per measurement property, according to the scoring system developed by Terwee and colleagues. ${ }^{22}$ For each test of a study, psychometric properties were assessed and were rated as adequate $(+)$, not adequate (-) or unclear (?). A rating of 0 was given when no information was available in the article. We then synthesised individual ratings using the criteria proposed by the Cochrane Back Review Group, leading to categories of strong evidence, moderate evidence, limited evidence, conflicting or unknown evidence. ${ }^{23}$

\section{Ethical}

Ethical approval and consent to participate are not applicable for this systematic review and analysis since no research subjects were recruited. This study adheres to the principles of the Declaration of Helsinki. ${ }^{24}$

\section{Results}

In Phase I for identifying cognitive tests, we included 319 articles. The flow of information through Phase I of the systematic review is presented in Figure 1. Of these 319 articles identified in our first search in 2017, 35 articles reported information on the psychometric properties of cognitive tests used in patients with ALS. In our second search conducted in 2019, we identified 11 new references reporting information on the psychometric properties of cognitive tests used in patients with ALS. A total of 46 articles were therefore included in Phase II of our 
Table I List of the Reported Psychometric Properties in Phase II - Definitions, Explanations and Recommendations of Preferred Statistical Method and Minimum Sample Size Included in Analyses

\begin{tabular}{|c|c|c|}
\hline $\begin{array}{l}\text { Psychometric Property - } \\
\text { Definition and Explanations }{ }^{21}\end{array}$ & Preferred Statistical Method $^{21}$ & $\begin{array}{l}\text { Sample } \\
\text { Size }^{21,22}\end{array}$ \\
\hline \multicolumn{3}{|l|}{ Internal consistency: } \\
\hline Internal consistency measures the degree of & -Cronbach's alpha & 50 \\
\hline $\begin{array}{l}\text { interrelatedness among items. Internal consistency is only relevant when items form a } \\
\text { reflective model, meaning all items are a manifestation of the same construct. }\end{array}$ & -Goodness of fit statistics & $100-500$ \\
\hline \multirow[t]{2}{*}{$\begin{array}{l}\text { Assessment of the unidimensionality of the test is a prerequisite for internal consistency } \\
\text { statistics to be evaluated objectively. }\end{array}$} & $\begin{array}{l}\text {-Factor analysis or item response } \\
\text { theory analysis }\end{array}$ & $100-500$ \\
\hline & $\begin{array}{l}\text {-Internal consistency coefficient for } \\
\text { each (unidimensional) (sub)scale } \\
\text { separately. }\end{array}$ & 50 \\
\hline \multicolumn{3}{|l|}{ Reliability: } \\
\hline Reliability is the degree to which a test is free from measurement error. & \multirow{3}{*}{$\begin{array}{l}\text {-ICC } \\
\text {-Cohen's kappa or weighted kappa } \\
\text { depending on the scale used. }\end{array}$} & \multirow[t]{3}{*}{50} \\
\hline $\begin{array}{l}\text {-Test-retest reliability refers to the robustness of the measurement error related to different } \\
\text { testing times. }\end{array}$ & & \\
\hline $\begin{array}{l}\text {-Interrater reliability refers to the robustness of the measure-error related to different } \\
\text { scorers. For evaluation of inter-rater reliability, the raters need to be independent. }\end{array}$ & & \\
\hline \multicolumn{3}{|l|}{ Content validity (including face validity) } \\
\hline \multicolumn{3}{|l|}{$\begin{array}{l}\text { Content validity represent the degree to which the content of a test adequately reflect the } \\
\text { construct to be measured. Content validity of a test is determined by asking patients for } \\
\text { patient-reported tests or experts within the field of interest to judge the relevance and } \\
\text { comprehensiveness of a test's items. Evaluation of face validity is subjective; therefore, no } \\
\text { standard exists. }\end{array}$} \\
\hline \multicolumn{3}{|l|}{ Construct validity } \\
\hline \multicolumn{3}{|l|}{$\begin{array}{l}\text { Construct validity represent the degree to which the scores of the test are consistent with } \\
\text { hypotheses based on the assumption that the test validly measures the construct to be } \\
\text { measured. }\end{array}$} \\
\hline $\begin{array}{l}\text {-The structural validity aspect of construct validity refers to the degree to which the score of } \\
\text { a test is an adequate reflection of the dimensionality of the construct to be measured. It is } \\
\text { only relevant for tests that are based on a reflective model. }\end{array}$ & -Factor analysis & 100 \\
\hline $\begin{array}{l}\text {-The hypothesis testing aspect of construct validity concerns the relationships to scores of } \\
\text { other instruments. It is recommended to formulate a priori hypotheses, to specify the } \\
\text { expected direction (positive or negative) of correlations one expects, or to quantify the range } \\
\text { of expected differences between groups or scores. It is important that the comparator test is } \\
\text { clearly described and has adequate measurement properties in order to interpret } \\
\text { correlations properly. }\end{array}$ & -Correlations & 50 \\
\hline \multicolumn{3}{|l|}{ Criterion validity } \\
\hline $\begin{array}{l}\text { Criterion validity refers to the degree to which the scores of a test are an adequate reflection } \\
\text { of a 'gold standard' (an external criterion of the phenomenon being measured). For health- } \\
\text { related patient reported outcome measures, the only possibility is to compare a shortened } \\
\text { version of a test to the original long version. }\end{array}$ & $\begin{array}{l}\text {-Correlations or the area under the } \\
\text { ROC. } \\
\text {-Sensitivity and specificity for } \\
\text { dichotomous scores }\end{array}$ & 50 \\
\hline
\end{tabular}

(Continued) 
Table I (Continued).

\begin{tabular}{|c|c|c|}
\hline $\begin{array}{l}\text { Psychometric Property - } \\
\text { Definition and Explanations }\end{array}$ & Preferred Statistical Method $^{21}$ & $\begin{array}{l}\text { Sample } \\
\text { Size }\end{array}$ \\
\hline \multicolumn{3}{|l|}{ Responsiveness } \\
\hline $\begin{array}{l}\text { Responsiveness is the ability of a test to detect change over time in the construct being } \\
\text { measured. When evaluating responsiveness, at a minimum, at least some of the patients } \\
\text { should display changed performance (eg, improvement or decrement). Therefore, it is } \\
\text { important to describe precisely what occurs during the follow-up. Responsiveness may be } \\
\text { evaluated by hypotheses testing or comparison to a 'gold standard'. }\end{array}$ & $\begin{array}{l}\text {-Hypotheses testing: Correlations } \\
\text {-Comparison to a gold standard: } \\
\text { Correlations or the area under the } \\
\text { ROC. } \\
\text {-Sensitivity and specificity for } \\
\text { dichotomous scores }\end{array}$ & 50 \\
\hline
\end{tabular}

Abbreviations: eg, for example; ICC, intraclass correlation coefficient; ROC, receiver operating characteristic.

systematic review. See Figure 2 for flow of information through Phase II of the systematic review.

\section{Phase I: Cognitive Tests Identified for Use in ALS-Specific Healthcare}

Table 2 lists the most frequently reported; cognitive tests classified into eight cognitive domains, test batteries, and rating scales evaluated in the included articles. The total number of tests referenced within each cognitive domain and the total number of times a test is referenced are shown.

A complete list of all cognitive tests identified in Phase I are presented in Supplementary material 2. We observed that for some tests, several different versions were used, which indicates that the tests were in the process of being developed or had been revised (eg the Wechsler Adult Intelligence Scale), or that the tests were modified or adapted specifically for use in patients with ALS.

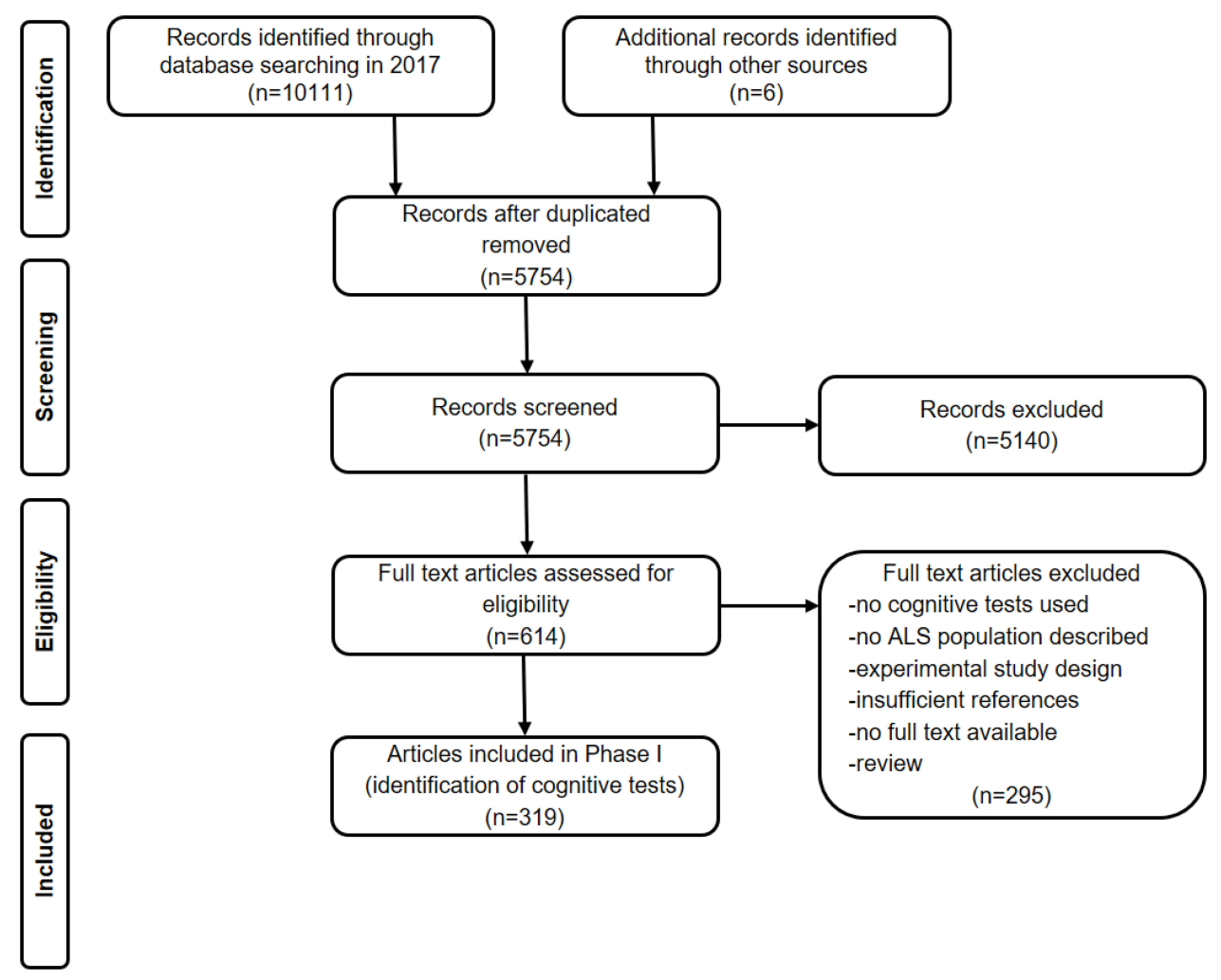

Figure I Flow of information through Phase I of the systematic review: Identifying cognitive tests.

Notes: Adapted from Liberati A, Altman D, Tetzlaff J, et al. The PRISMA statement for reporting systematic reviews and meta-analyses of studies that evaluate health care interventions: explanation and elaboration. J Clin Epidemiol. 2009;62:10. Creative Commons license and disclaimer available from: http://creativecommons.org/licenses/by/4. 0/legalcode. ${ }^{12}$

Abbreviation: ALS, amyotrophic lateral sclerosis. 


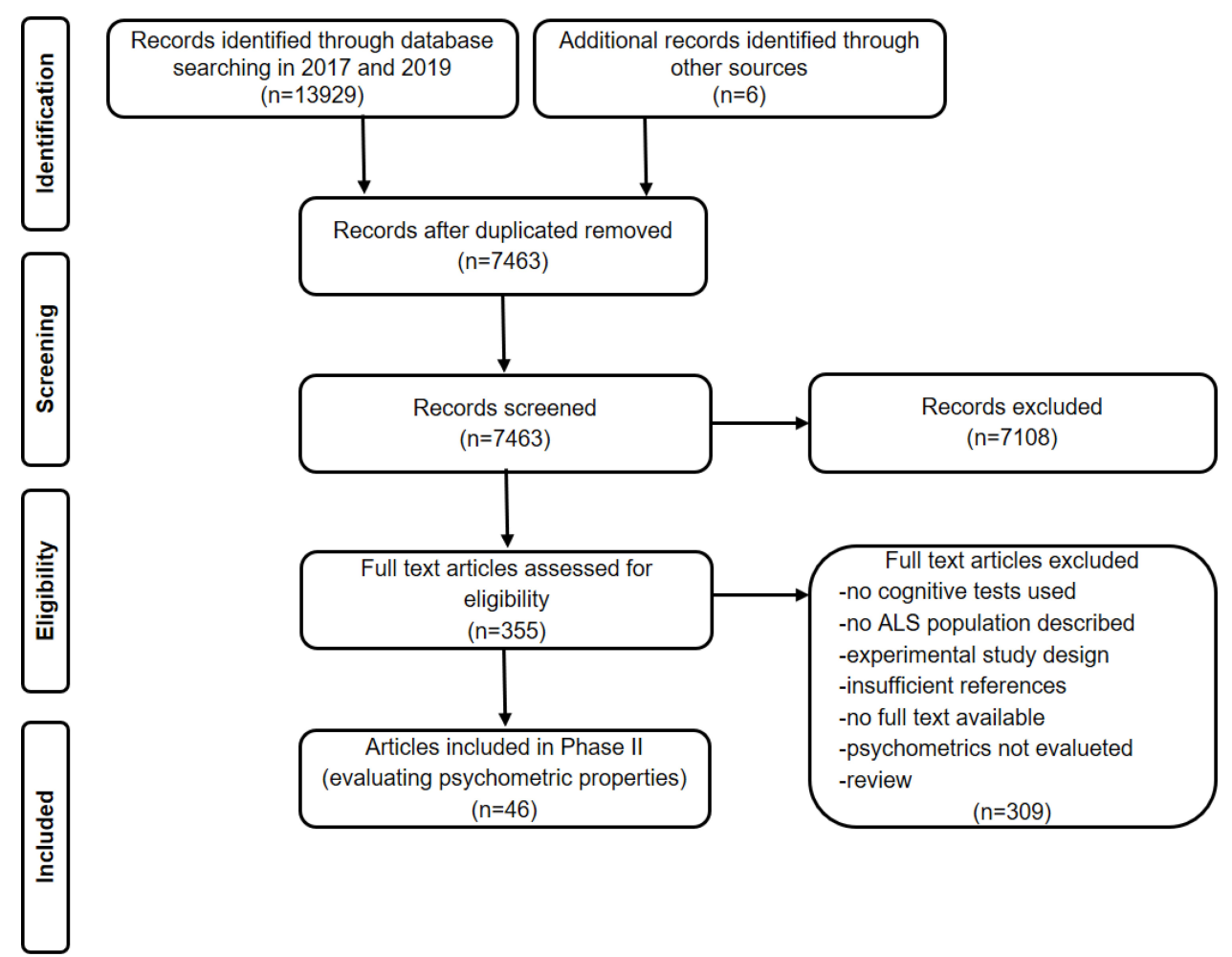

Figure 2 Flow of information through Phase II of the systematic review: Evaluating psychometric properties.

Notes: Adapted from Liberati A, Altman D, Tetzlaff J, et al. The PRISMA statement for reporting systematic reviews and meta-analyses of studies that evaluate health care interventions: explanation and elaboration. J Clin Epidemiol. 2009;62:10. Creative Commons license and disclaimer available from: http://creativecommons.org/licenses/by/4. 0/legalcode. ${ }^{12}$

Abbreviation: ALS, amyotrophic lateral sclerosis.

\section{Phase II: Cognitive Tests That Were Evaluated in Patients with ALS}

Table 3 summarises the characteristics of articles and studies reported therein that were included in Phase II of this review. All of the included studies reporting on feasibility of tests, focused on the suitability of specific tests for use in patients with motor and speech impairment. The authors of those studies indicated that the Edinburgh Cognitive and Behavioural ALS screen (ECAS) might be more suitable for patients with ALS than the Frontal Assessment Battery (FAB) and the Montreal Cognitive Assessment (MoCA) screening test. Table 4 lists cognitive tests evaluated in patients with ALS identified in the first (2017) and second search (2019) of the review, and examined in Phase II according to their cognitive domain classification. Available in Table 4 is also information in which country each test has been validated.

\section{Phase II: Assessment of Study Quality}

Assessment of the methodological quality of included studies using the COSMIN checklist ${ }^{21}$ was for each psychometric property of interest (see Table 1 for definitions and explanations):

\section{Internal Consistency}

None of the nine studies evaluating internal consistency explicitly described whether the tests used were based on a reflective or formative model. Nonetheless, all of the nine studies calculated Cronbach's alpha or Item response theory (IRT), methods that are both adequate parameters of internal consistency. Four studies assessed the unidimensionality of the test they used. Of these four studies, two conducted the unidimensional subtest separately, and all four had a sample size of greater than 50 .

\section{Reliability}

None of the five studies that assessed reliability evaluated test-retest reliability. For evaluation of inter-rater reliability, the raters were independent in four studies. Three studies used intraclass correlation coefficient, a preferred statistical measure of reliability. Two studies used Pearson's correlation, which does not take systematic error into account. Two studies had a sample size of less than 50 participants. 
Table 2 List of the Most Frequently Reported Cognitive Tests, Test Batteries and Scales Used in Patients with Amyotrophic Lateral Sclerosis (ALS) in 319 Articles Identified in Phase I

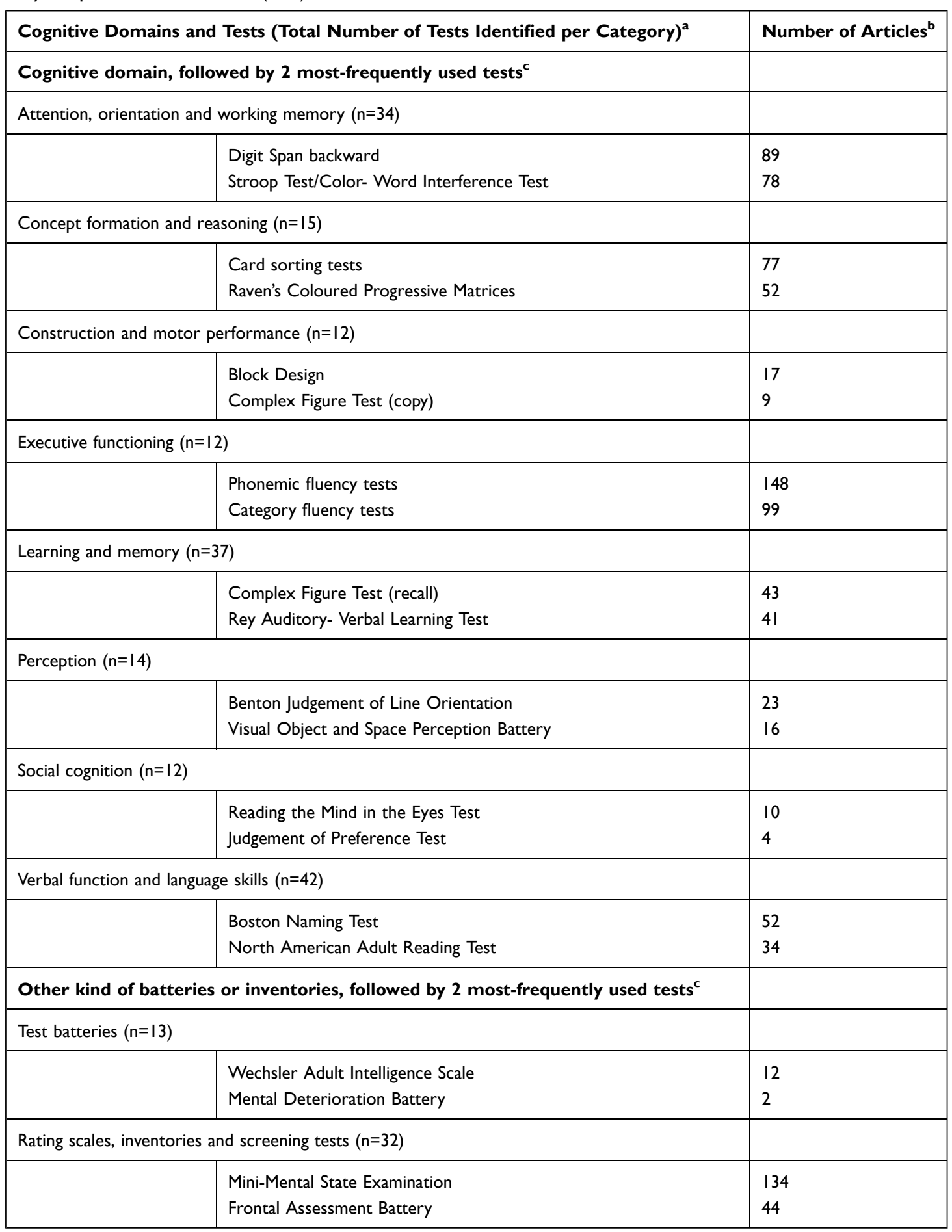

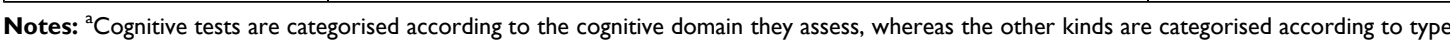
of test (eg, scale, battery, etc.), as indicated. ${ }^{b} \mathrm{~A}$ given article could report on more than one test. ${ }^{\mathrm{C} S e e}$ Supplemental material 2 for the complete list of all reported tests.

\section{Content Validity}

One study assessed the content validity of the test they used; however, they did not provide a detailed description of how this was done.

\section{Construct Validity - Structural Validity}

None of the four studies evaluating structural validity explicitly described whether the tests they used were based on a reflective or formative model. Three studies used IRT 
Table 3 Characteristics of Articles Included in Phase II

\begin{tabular}{|l|l|}
\hline Study Characteristics & Values \\
\hline Articles, number & 46 \\
Publication year, range & $1985-2019$ \\
ALS-sample size per study, range & $5-274$ \\
Mean age (year) of ALS patients, range & $50.7-68.5$ \\
\hline Recruitment setting, number of articles & \\
Hospital or clinical & 40 \\
Register data & 2 \\
Others & 4 \\
\hline Continent, number of articles & \\
America & 14 \\
Asia & 6 \\
Europe & 22 \\
Oceania & 4 \\
\hline Study design, number of articles & \\
Cross sectional & 38 \\
Longitudinal & 8 \\
Cohort study & 3 \\
Case-control & 19 \\
Diagnostic & 22 \\
Combination of designs & 2 \\
\hline Psychometrics, number of articles & \\
Internal consistency & 5 \\
Reliability & 5 \\
Content validity & 1 \\
Construct validity - structural validity & 4 \\
Construct validity - hypothesis testing & 28 \\
Criterion validity & \\
Responsiveness & \\
\hline
\end{tabular}

Abbreviation: ALS, amyotrophic lateral sclerosis.

methods and followed the recommendation of checking the dimensionality of the items. One study that relied on classical test theory did not use factor analysis for this check, which is the preferred statistical method to determine the structure of the instrument.

\section{Construct Validity - Hypothesis Testing}

Of 28 studies evaluating hypothesis testing, 26 studies formulated a priori hypotheses. Specification of expected direction (positive or negative) of correlations one expected, or quantification of the range of expected differences between groups or scores were lacking completely or described only vaguely in 23 studies. Of the 14 studies that used hypothesis testing to investigate the convergent validity of tests, all 14 studies provided references for the comparator test; however, eight of these studies lacked information about measurement properties. In 27 studies, correlations were used. In seven studies, the sample size was inadequate.

\section{Criterion Validity}

In 24 of 29 studies evaluating criterion validity, we found that the authors compared the scores of the new test to a widely used one, not the original longer version. Statistic methods like correlation, receiver operating characteristics and sensitivity/specificity were used in all 24 studies. The sample size were inadequate in eight studies.

\section{Responsiveness}

All the three studies evaluating responsiveness tested the subjects at least two times during the assessment period and reported the time interval between measurements. Precise descriptions of what occurs during the follow-up were not adequately described in any of the included studies. To evaluate responsiveness, all three included studies tested a specific hypothesis. All three studies formulated hypotheses a priori, but the hypotheses were formulated only vaguely. Two studies reported p-values for the hypothesis testing they did, even if this should be avoided since it is not relevant to examine whether correlations statistically differ from zero. ${ }^{70}$ The sample size in the analyses were too small in all the included studies.

\section{Phase II - Synthesis of Evidence}

The results from the synthesis of the evidence on the quality of the test psychometrics in Phase II of this review are presented in Table 5.

We found that the highest level of evidence was supported for the screening tests; Addenbrooke's Cognitive Evaluation (ACE) and Frontal Assessment Battery (FAB), and the Reading the Mind in the Eye Test (RME), a test of social cognition. We found support for a moderate level of evidence for the ECAS and the MoCA screening tests and the Awareness of Social Inference Test, another test of social cognition. It should be noted that when evaluating the quality of screening tools, only the ECAS has alternative versions limiting practice effects. Moreover, it is available in several languages. Of all the included articles in Phase II, we observed that the greatest number of psychometric properties of interest was evaluated for the ACE and the ECAS. The Mini-Mental State Examination (MMSE) showed inconsistent levels of evidence. 
Table 4 List of Cognitive Tests Evaluated in an ALS Population, Identified in the First and Second Search (2017 and 2019$)$ of the Review and Examined in Phase II, Classified into Cognitive Domains

\begin{tabular}{|c|c|c|}
\hline Test & $\begin{array}{l}\text { Country of Validation } \\
\text { (Alphabetical Order) }\end{array}$ & $\begin{array}{l}\text { Reference } \\
\text { Number }\end{array}$ \\
\hline $\begin{array}{l}\text { Executive functioning } \\
\text { Category fluency tests } \\
\text { Phonemic fluency tests }\end{array}$ & $\begin{array}{l}\text { Italy } \\
\text { Italy, Scotland }\end{array}$ & $\begin{array}{l}25 \\
25,26\end{array}$ \\
\hline $\begin{array}{l}\text { Learning and memory } \\
\text { Prospective memory test }\end{array}$ & China & 27 \\
\hline $\begin{array}{l}\text { Social cognition } \\
\text { Awareness of Social Inference Test } \\
\text { Ekman } 60 \text { Faces Test } \\
\text { Reading the Mind in the Eyes Test }\end{array}$ & $\begin{array}{l}\text { Australia } \\
\text { England } \\
\text { Ireland }\end{array}$ & $\begin{array}{l}28 \\
29 \\
30\end{array}$ \\
\hline $\begin{array}{l}\text { Screening tests } \\
\text { Addenbrooke's Cognitive Examination } \\
\text { ALS Brief Cognitive Assessment } \\
\text { ALS Cognitive Behavioural Screen } \\
\text { Edinburgh Cognitive and Behavioural ALS Screen } \\
\text { Frontal Assessment Battery } \\
\text { Mini-Mental State Examination } \\
\text { Montreal Cognitive Assessment } \\
\text { Penn State Brief Exam of Frontal and Temporal Dysfunction Syndromes } \\
\text { University of California San Francisco Screening Battery }\end{array}$ & $\begin{array}{l}\text { Australia, Canada, China, Greece, Japan } \\
\text { United States of America } \\
\text { Brazil, Italy, Spain, United States of America } \\
\text { China, Czech Republic, Germany, Greece, } \\
\text { Ireland, Scotland, Spain, Switzerland } \\
\text { Australia, Canada, Italy, Japan, Korea, United } \\
\text { States of America } \\
\text { China, Italy, United States of America } \\
\text { Canada, Japan } \\
\text { United States of America } \\
\text { United States of America }\end{array}$ & $\begin{array}{l}31-36 \\
37 \\
38-42 \\
5,35,43-53 \\
25,36,54-58 \\
25,34,37 \\
55,58 \\
59 \\
60,61\end{array}$ \\
\hline $\begin{array}{l}\text { Test batteries }^{\mathrm{a}} \\
\text { ALS-Computerized Frontal Battery } \\
\text { Battery I: Frontal Behavioral Inventory, Phonemic fluency test, Beck Depression } \\
\text { Inventory }\end{array}$ & $\begin{array}{l}\text { Canada } \\
\text { United States of America }\end{array}$ & $\begin{array}{l}62 \\
63\end{array}$ \\
\hline $\begin{array}{l}\text { Battery II: Addenbrooke's Cognitive Examination-Revised, Digit Span-backword, } \\
\text { Hayling Test, lowa Gambling Test, Ekman } 60 \text { Faces-modified, Cambridge Behavioural } \\
\text { Inventory-Revised } \\
\text { Battery III: ALS Cognitive Behavioural Screen, Phonemic fluency test, Semantic } \\
\text { fluency test, Boston Naming Test-short version, Comprehension of Instructions, }\end{array}$ & Greece & 65 \\
\hline $\begin{array}{l}\text { Peabody Picture Vocabulary Test-Revised } \\
\text { Battery IV: Token Test-modified, Graded Naming Test, British Picture Vocabulary } \\
\text { Scale-II, Test for the Reception of Grammar, Pyramids and Palm Trees Test, Kissing } \\
\text { and Dancing Test, Cookie Theft Picture }\end{array}$ & England & 66 \\
\hline $\begin{array}{l}\text { Battery V: Frontal Behavioural Inventory-Modified, Mini-Mental State Examination, } \\
\text { Rey Auditory- Verbal Learning Test, Controlled Oral Word Fluency Test } \\
\text { Communicative Participation Item Bank } \\
\text { Mental Deterioration Battery }\end{array}$ & $\begin{array}{l}\text { United States of America } \\
\text { United States of America } \\
\text { Italy }\end{array}$ & $\begin{array}{l}68 \\
69\end{array}$ \\
\hline
\end{tabular}

Notes: ${ }^{a}$ Batteries $I-V$ were developed specifically for use in patients with ALS.

Abbreviation: ALS, amyotrophic lateral sclerosis.

\section{Discussion}

In this review, we had two aims: (i) to compile a comprehensive list of all cognitive tests used in ALSspecific healthcare and (ii) to provide a descriptive synthesis of the psychometric properties of tests validated in patients with ALS.
Our literature search and analyses indicated that a large number of tests are being used in ALS-specific healthcare. Of these tests, however, only a fraction have been evaluated for use within a population of ALS patients. This may lead to different conclusions about a patient's cognitive functioning. ${ }^{22}$ Although commonly used, some tests, 
Table 5 Levels of Evidence: Quality of Psychometric Properties and Feasibility of Tests in Articles Identified During Phase II

\begin{tabular}{|c|c|c|c|c|c|c|c|c|}
\hline Test & $\begin{array}{l}\text { Internal } \\
\text { Consistency }\end{array}$ & Reliability & $\begin{array}{l}\text { Content } \\
\text { Validity }\end{array}$ & $\begin{array}{l}\text { Structural } \\
\text { Validity }\end{array}$ & $\begin{array}{l}\text { Hypothesis } \\
\text { Testing }\end{array}$ & $\begin{array}{l}\text { Criterion } \\
\text { Validity }\end{array}$ & Responsiveness & Feasibility \\
\hline $\begin{array}{l}\text { Executive } \\
\text { Category fluency tests } \\
\text { Phonemic fluency tests }\end{array}$ & & & & & $?$ & $?$ & & \\
\hline $\begin{array}{l}\text { Learning memory } \\
\text { Prospective memory test }\end{array}$ & & & & & $?$ & & & \\
\hline $\begin{array}{l}\text { Social cognition } \\
\text { Awareness of Social Inference } \\
\text { Test } \\
\text { Ekman } 60 \text { Faces Test } \\
\text { Reading the Mind in the Eyes Test }\end{array}$ & +++ & & & +++ & $\begin{array}{l}++ \\
?\end{array}$ & & & \\
\hline $\begin{array}{l}\text { Screening test } \\
\text { Addenbrooke's Cognitive } \\
\text { Examination } \\
\text { ALS Brief Cognitive Assessment } \\
\text { ALS Cognitive Behavioural } \\
\text { Screen } \\
\text { Edinburgh Cognitive and } \\
\text { Behavioural ALS Screen } \\
\text { Frontal Assessment Battery } \\
\text { Mini-Mental State Examination } \\
\text { Montreal Cognitive Assessment } \\
\text { Penn State Brief Exam of Frontal } \\
\text { and Temporal Dysfunction } \\
\text { Syndromes } \\
\text { University of California San } \\
\text { Francisco Screening Battery }\end{array}$ & ? & . & & ? & $\begin{array}{l}++ \\
+++ \\
++\end{array}$ & $\begin{array}{l}++ \\
? \\
+/- \\
?\end{array}$ & 更 & $\begin{array}{l}x \\
x \\
x \\
x \\
x\end{array}$ \\
\hline $\begin{array}{l}\text { Test batteries a } \\
\text { ALS-Computerized Frontal } \\
\text { Battery } \\
\text { Battery I } \\
\text { Battery II } \\
\text { Battery III } \\
\text { Battery IV } \\
\text { Battery V } \\
\text { Communicative Participation } \\
\text { Item Bank } \\
\text { Mental Deterioration Battery }\end{array}$ & + & $?$ & $?$ & . & ? & ? & & $\mathrm{x}$ \\
\hline
\end{tabular}

Notes: +++ or $-=$ Strong evidence with consistent positive or negative results from multiple studies with good methodological quality or one study with excellent methodological quality. ++ or $-=$ Moderate evidence with consistent positive or negative results from multiple studies with fair methodological quality or one study with good quality. + or $-=$ Limited evidence with positive or negative results from a study with fair methodological quality. $+/-=$ Conflicting evidence with conflicting results from

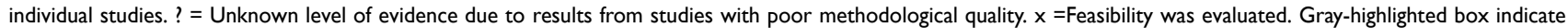
high to moderate level of evidence. ${ }^{a}$ Batteries I-V were developed specifically for use in patients with ALS.

Abbreviation: ALS, amyotrophic lateral sclerosis.

especially the MMSE, have produced conflicting evidence when it comes to assessing ALS-specific cognitive changes. ${ }^{25,34,56,67}$

To date, of the tests used to evaluate cognitive changes in ALS, none fulfils all of the essential measurement properties stipulated by the COSMIN checklist. $^{21} \mathrm{We}$ did, however, observe acceptable measurement properties for four screening tests; the ACE, FAB, ECAS and MoCA. Feasibility studies, however, showed that the ECAS might be more suitable, and hence preferable, for screening cognitive function in ALS patients compared to the FAB and MoCA, a finding that is in line with that of another systematic review. ${ }^{71}$ While several screening tests have been developed to detect cognitive changes, the 
ECAS has been designed specifically to assess cognitive changes in patients with ALS. ${ }^{5}$ Strong et al recommend that either the ECAS or the ALS-CBS be administered to all patients. ${ }^{1}$ However, in our review, we found the psychometric properties of the ALS-CBS poorly evaluated. Our analysis revealed that, of all the screening tests evaluated in the included studies, the psychometric properties of the ECAS and ACE were the most scrutinised. It should be noticed, however, that effort has been made to provide alternate versions of the ECAS. ${ }^{72}$ The challenge in recurrent testing is that the disease may sometimes deteriorate quickly. Therefore, the tests should be easy to perform, but not be easily remembered and learned at the same time. This enables recurrent testing which is desirable to follow the development of cognitive changes over time. This way, significant practice effects can be reduced if not eliminated. Moreover, translations in several languages would allow international multicentre studies, which could increase knowledge and patient care.

Of two tests of social cognition evaluated in patients with ALS, we found that the highest level of evidence was supported for the RME. Although not specifically developed for use in patients with ALS, the RME accounts for potential physical disability as it can be conducted in either written or spoken. ${ }^{73}$ The RME is recommended by Strong et al for evaluation of the ability to read the emotions of others, a social cognitive process most likely in patients with ALS who meet the criteria for frontotemporal dementia. ${ }^{1}$

Our data suggest that the ECAS may be preferred over other screening tests for validly and reliably screening cognitive change in patients with ALS and that the RME may be suitable for the extended assessment of social cognition. The advantage of ECAS is that it is an ALSspecific test and therefore may show changes that are characteristic for ALS. However, our data did not allow us to give clear recommendations on which specific tests to use for extended assessment of other cognitive changes that may occur in patients with ALS. Similar methodological flaws recurring across the included studies preclude us from making such recommendations, and also prompt us to highlight the need for researchers and clinicians to pay particular attention to the methods applied in psychometric studies. Hence, there is a great potential for improving the methodological quality of studies that aim to evaluate the measurement properties of a cognitive test used in ALS-specific healthcare.

\section{Study Strengths and Limitations}

The strengths of the current study lay in the rigorous quality assessment achieved by the use of the COSMIN checklist, a widely used and validated tool to assess the risk of bias in evaluating measurement properties of a test. ${ }^{21}$ Also, in combination with the COSMIN checklist, we used recommended quality criteria $^{21}$ to synthesise the level of evidence. ${ }^{22}$ Other strengths are that a trained librarian conducted the literature search and that the searches were relatively comprehensive and exhaustive. However, we did not consult all databases, nor grey literature, a strategy that future reviews might consider.

This review did not take studies in healthy controls into account. A more accurate reflection of the psychometric properties of each test would include studies with healthy controls. Therefore, the reliability and validity of some tests may be underestimated. The analyses demonstrate that in particular, screening instruments have been evaluated so far, and more research is needed with regard to evaluate further cognitive/neuropsychological tests. Another limitation can be the inclusion of articles since 1985, since this may risk confusing the results as different versions of cognitive tests may have varying psychometric properties. We argue that our aim was to provide a comprehensive overview possibly also including results from countries where not all tests/versions are available yet. Furthermore, the analyses in the present study are limited to the assessment of cognition as one aspect of behavior. We acknowledge the importance to investigate tests assessing emotional aspects of behavior as a future.

The quality of included studies was rated as fair to poor in many cases, which limits the conclusions we can draw. Available data did not allow us to conduct meta-analyse and we could not perform assessments of heterogeneity. Thus, at this point, we can only give guarded advice for tests that should be used in ALS-specific healthcare. We are aware that the presence of publication bias may have affected our results. Finally, some evaluator bias may have also affected our result, because three of the authors of this review are involved in the validation of the Norwegian version of the ECAS. ${ }^{74}$

\section{Conclusions}

To the best of our knowledge, this is the first study to systematically identify and evaluate tests that are used to measure the cognitive change in ALS and those tests that 
have been validated in patients with ALS. The screening test, ECAS and the social cognition test, RME; may have some advantages over other tests that have been used for assessing cognitive change in ALS patients. Psychometric properties of tests that were evaluated in a population of ALS patients have mainly been examined in screening instruments. Thus, more research regarding the validation of comprehensive neuropsychological assessment seems appropriate to implement the recent ALS criteria. ${ }^{1}$

\section{Acknowledgments}

The authors thank Professor Hans Lund at the Western Norway University of Applied Sciences, Bergen for sharing his extensive experience in conducting systematic reviews and generously providing advice along the way.

\section{Disclosure}

Tina Taule reports three of the authors of this review are involved in the validation of the Norwegian version of the ECAS. The authors report no other potential conflicts of interest for this work. This work was funded by grants from the Western Regional Norwegian Health Authority [grant number: 912,158, 2017].

\section{References}

1. Strong M, Abrahams S, Goldstein L, et al. Amyotrophic lateral sclerosis - frontotemporal spectrum disorder (ALS-FTSD): revised diagnostic criteria. Amyotroph Lateral Scler Frontotemporal Degener. 2017;18:153-174.

2. Olney R, Murphy J, Forwhew D, et al. The effects of executive and behavioral dysfunction on the course of ALS. Neurology. 2005;65:1774-1777. doi:10.1212/01.wnl.0000188759.87240.8b

3. Pagnini F, Rossi G, Lunetta C, et al. Burden, depression, and anxiety in caregivers of people with amyotrophic lateral sclerosis. Psychol Health Med. 2010;15(6):685-693. doi:10.1080/13548506.2010. 507773

4. Khin E, Minor D, Holloway A, Pelleg A. Decisional capacity in amyotrophic lateral sclerosis. $J$ Am Acad Psychiatry Law. 2015;43:210-217.

5. Abrahams S, Newton J, Niven E, Foley G, Bak T. Screening for cognition and behaviour changes in ALS. Amyotroph Lateral Scler Frontotemporal Degener. 2014;15(12):9-14. doi:10.3109/ 21678421.2013.805784

6. Bock M, Duong Y-N, Kim A, Allen I, Murphy J, Lomen-Hoerth C. Cognitive-behavioral changes in amyotrophic lateral sclerosis: screening prevalence and impact on patients and caregivers. Amyotroph Lateral Scler Frontotemporal Degener. 2016;17(56):366-373. doi:10.3109/21678421.2016.1165257

7. Beeldman E, Raaphorst J, Twennaar M, deVisser M, Schmand B, de Haan R. The cognitive profile of ALS: a systematic review and meta-analysis update. J Neurol Neurosurg Psychiatry. 2015;87 (6):611-619. doi:10.1136/jnnp-2015-310734

8. Woolley S, Katz J. Cognitive and behavioral impairment in amyotrophic lateral sclerosis. Phys Med Rehabil Clin N Am. 2008;19 (3):607-617. doi:10.1016/j.pmr.2008.04.002
9. Crockford CJ, Newton J, Lonergan K, et al. ALS-specific cognitive and behavior changes associated with advancing disease stage in ALS. Neurology. 2018;91.

10. Raaphorst J, de Visser M, Linssen WH, De Haan R, Schmand B. The cognitive profile of amyotrophic lateral sclerosis: a meta-analysis. Amyotrophic Lateral Sclerosis. 2010;11(12):27-37. doi:10.3109/ 17482960802645008

11. Woolley SC. Utility of the amyotrophic lateral sclerosis cognitive behavioral screen (ALS CBS ${ }^{\mathrm{TM}}$ ). Neurodegen Dis Manage. 2011;1 (6):473-479. doi:10.2217/nmt.11.63

12. Liberati A, Altman D, Tetzlaff J, et al. The PRISMA statement for reporting systematic reviews and meta-analyses of studies that evaluate health care interventions: explanation and elaboration. $J$ Clin Epidemiol. 2009;62:10. doi:10.1016/j.jclinepi.2008.05.006

13. Taule T, Søvik M, Lein R, Wehling E, Aßmus J, Rekand T Cognitive assessment tools used in ALS-specific health-care: a systematic review of their psychometric properties. 2017; Available from: http://www.crd.york.ac.uk/PROSPERO/display_record.php?ID= CRD42017055603. Accessed August 15, 2020.

14. Brooks B, Miller R, Swash M, Munsat M. World federation of neurology research group on motor neuron diseases. El Escorial revisited: revised criteria for the diagnosis of amyotrophic lateral sclerosis. Amyotroph Lateral Scler Other Motor Neuron Disord. 2000;1(5):293-299. doi:10.1080/146608200300079536

15. de Carvalho M, Dengler R, Eisen A, et al. Electrodiagnostic criteria for diagnosis of ALS. Clin Neurophysiol. 2008;119(3):497-503. doi:10.1016/j.clinph.2007.09.143

16. Brooks B. El escorial world federation of neurology criteria for the diagnosis of amyotrophic lateral sclerosis. Subcommittee on motor neuron diseases/amyotrophic lateral sclerosis of the World federation of neurology research group on neuromuscular diseases and the El Escorial "Clinical limits of amyotrophic lateral sclerosis" workshop contributors. J Neurol Sci. 1994;124:96-107. doi:10.1016/0022-510x (94)90191-0

17. Clinical queries using research methodology filters. PubMed help [Internet] - Clinical queries using research methodology filters; 2005. Available from: https://www.ncbi.nlm.nih.gov/books/ NBK3827/table/pubmedhelp.T.clinical_queries_using_rese/.

Accessed August 15, 2020.

18. Wong S, Wilczynski N, Haynes R, Ramkissoonsingh RHT. Developing optimal search strategies for detecting sound clinical prediction studies in MEDLINE. AMIA Annu Symp Proc. 2003;728-732.

19. Strauss E, Sherman E, Spreen O. A Compendium of Neuropsychological Tests. 3rd ed. Oxford, England, UK: Oxford: University Press; 2006.

20. Lezak M, Howieson D, Bigler E, Tranel D. Neuropsychological Assessment. 5 revised ed. Oxford, England, UK: Oxford University Press Inc; 2012.

21. Mokkink L, Terwee C, Patrick D, et al. The COSMIN checklist for assessing the methodological quality of studies on measurement properties of health status measurement instruments: an international Delphi study. Qual Life Res. 2010;19(4):539-549. doi:10.1007/ s11136-010-9606-8

22. Terwee C, Bot S, de Boer M, et al. Quality criteria were proposed for measurement properties of health status questionnaires. $J$ Clin Epidemiol. 2007;60(1):34-42. doi:10.1016/j.jclinepi.2006.03.012

23. vanTulder M, Furland A, Bombardier C, Bouter L. Editorial board of the Cochrane back review group. Updated method guidelines for systematic reviews in the cochrane collaboration back review group. Spine. 2003;28:1290-1299. doi:10.1097/01.BRS.0000065484. 95996.AF

24. World medical association. World medical association declaration of Helsinki - Ethical principles for medical research involving human subjects. JAMA. 2013;310(20):2191-2194. doi:10.1001/jama.2013. 281053 
25. Floris G, Borghero G, Chiò A, et al. Cognitive screening in patients with amyotrophic lateral sclerosis in early stages. Amyotroph Lateral Scler. 2012;13:95-101. doi:10.3109/17482968.2011.605453

26. Abrahams S, Leigh P, Harvey A, Vythelingum G, Grise D, Goldstein L. Verbal fluency and executive dysfunction in amyotrophic lateral sclerosis (ALS). Neuropsychologia. 2000;38 (6):734-747. doi:10.1016/S0028-3932(99)00146-3

27. Ji Y, Wei L, Chui D, Wang K, Fan D. Prospective memory tasks: a more sensitive method for screening cognitive impairment in ALS? BMC Neurol. 2012;12:142. doi:10.1186/1471-2377-12-142

28. Staios M, Fisher F, Lindell A, Ong B, Howe J, Reardon K. Exploring sarcasm detection in amyotrophic lateral sclerosis using ecologically valid measures. Front Hum Neurosci. 2013;7:178. doi:10.3389/ fnhum.2013.00178

29. Papps B, Abrahams S, Wicks P, Leigh P, Goldstein L. Changes in memory for emotional material in amyotrophic lateral sclerosis (ALS). Neuropsychologia. 2005;43(8):1107-1114. doi:10.1016/j. neuropsychologia.2004.11.027

30. Burke T, Pinto-Grau M, Lonergan K, et al. Measurement of social cognition in amyotrophic lateral sclerosis: a population based study. PLoS One. 2016;11:8. doi:10.1371/journal.pone.0160850

31. Chenji S, Mah D, Johnston W, Camicioli R, Fisher N, Kalra S. Utility of the Addenbrooke's cognitive examination in amyotrophic lateral sclerosis. Can J Neurol Sci. 2018;45(5):527-532. doi:10.1017/ cjn. 2018.68

32. Hsieh S, Caga J, Leslie F, et al. Cognitive and behavioral symptoms in ALSFTD: detection, differentiation, and progression. J Geriatr Psychiatry Neurol. 2016;29(1):3-10. doi:10.1177/0891988715598232

33. Masuda M, Watababe H, Tanaka Y, et al. Age-related impairment in Addenbrooke's cognitive examination revised scores in patients with amyotrophic lateral sclerosis. Amyotroph Lateral Scler Frontotemporal Degener. 2018;19(78):578-584. doi:10.1080/ 21678421.2018.1510009

34. Wei Q, Chen X, Zheng Z, et al. Screening for cognitive impairment in a Chinese ALS population. Amyotroph Lateral Scler Frontotemporal Degener. 2015;16(12):40-45. doi:10.3109/21678421.2014.966311

35. Kourtesis P, Christidi F, Margioti E, et al. The Edinburgh cognitive and behavioral amyotrophic lateral sclerosis screen (ECAS): sensitivity in differentiating between ALS and Alzheimer's disease in a Greek population. Amyotroph Lateral Scler Frontotemporal Degener. 2019;30:1-8.

36. Xu Z, Alruwaili A, Henderson R, McCombe P. Screening for cognitive and behavioural impairment in amyotrophic lateral sclerosis: frequency of abnormality and effect on survival. J Neurol Sci. 2017;376:16-23. doi:10.1016/j.jns.2017.02.061

37. $\mathrm{Hu} \mathrm{W}$, Shelnutt M, Wilson A, et al. Behavior matters-cognitive predictors of survival in amyotrophic lateral sclerosis. PLoS One. 2013;8:2.

38. Murphy J, Factor-Litvak P, Goetz R, et al. Cognitive-behavioral screening reveals prevalent impairment in a large multicenter ALS cohort Neurology. 2016;86(9):813-820. doi:10.1212/WNL.0000000000002305

39. Woolley SC, York MK, Moore DH, et al. Detecting frontotemporal dysfunction in ALS: utility of the ALS cognitive behavioral screen (ALS-CBS). Amyotroph Lateral Scler. 2010;11(3):303-311. doi:10.3109/17482961003727954

40. Branco L, De-Rezende T, Casseb R, Balthazar M, Woolley S, Franca M. Transcultural validation of the ALS-CBS cognitive section for the Brazilian population. Amyotroph Lateral Scler Frontotemporal Degener. 2017;18(12):60-67. doi:10.1080/21678421.2016.1211147

41. Tremolizzo L, Lizio A, Santangelo G, et al. ALS cognitive behavioral screen (ALS-CBS): normative values for the Italian population and clinical usability. Neurol Sci. 2019.

42. Turon-Sans J, Gascon-Bayarri J, Reñé R, et al. Cognitive impairment in ALS patients and validation of the Spanish version of the ALS-CBS test. Amyotroph Lateral Scler Frontotemporal Degener. 2016;17(34):221-227. doi:10.3109/21678421.2015.1125500
43. Burkhardt C, Neuwirth C, Weber M. Longitudinal assessment of the Edinburgh cognitive and behavioural amyotrophic lateral sclerosis screen (ECAS): lack of practice effect in ALS patients? Amyotroph Lateral Scler Frontotemporal Degener. 2017;18(34):202-209. doi:10.1080/21678421.2017.1283418

44. Niven E, Newton J, Foley J, et al. Validation of the Edinburgh cognitive and behavioural amyotrophic lateral sclerosis screen (ECAS): A cognitive tool for motor disorders. Amyotroph Lateral Scler Frontotemporal Degener. 2015;16(34):172-179. doi:10.3109/ 21678421.2015.1030430

45. Pinto-Grau M, Burke T, Lonergan K, et al. Screening for cognitive dysfunction in ALS: validation of the Edinburgh cognitive and behavioural ALS screen (ECAS) using age and education adjusted normative data. Amyotroph Lateral Scler Frontotemporal Degener. 2017;18(12):99-106. doi:10.1080/21678421.2016.1249887

46. Lule D, Hörner K, Vazquez C, et al. Screening for cognitive function in complete immobility using brain-machine interfaces: A proof of principle study. Front Neurosci. 2018;12:517. doi:10.3389/ fnins.2018.00517

47. Ye S, Li C, Liu X, Fan D. The Edinburgh cognitive and behavioural ALS screen in a Chinese amyotrophic lateral sclerosis population. PlosOne. 2016;11:5.

48. Lulé D, Burkhardt C, Abdulla S, et al. The Edinburgh cognitive and behavioural amyotrophic lateral sclerosis screen: a cross-sectional comparison of established screening tools in a German-Swiss population. Amyotroph Lateral Scler Frontotemporal Degener. 2015;16(12):16-23. doi:10.3109/21678421.2014.959451

49. Keller J, Krimly A, Bauer L, et al. A first approach to a neuropsychological screening tool using eye-tracking for bedside cognitive testing based on the Edinburgh cognitive and behavioural ALS screen. Amyotroph Lateral Scler Frontotemporal Degener. 2017;18(56):443-450. doi:10.1080/ 21678421.2017.1313869

50. Poletti B, Solca F, Carelli L, et al. The validation of the Italian Edinburgh cognitive and behavioural ALS screen (ECAS). Amyotroph Lateral Scler Frontotemporal Degener. 2016;17 (78):489-498. doi:10.1080/21678421.2016.1183679

51. Poletti B, Solca F, Carelli L, et al. Cognitive-behavioral longitudinal assessment in ALS: the Italian Edinburgh cognitive and behavioral ALS screen (ECAS). Amyotroph Lateral Scler Frontotemporal Degener. 2018;19:387-395. doi:10.1080/ 21678421.2018.1473443

52. Mora J, Salas T, Fernández M, Rodriguez-Castillo V, Chaverri D, Rodriguez-Santos F. Spanish adaptation of the Edinburgh cognitive and behavioral amyotrophic lateral sclerosis screen (ECAS). Amyotroph Lateral Scler Frontotemporal Degener. 2018;19 (12):74-79. doi:10.1080/21678421.2017.1406952

53. Bezdíček O, Marková L, Soósová N, Forgáč M. Czech version of the Edinburgh cognitive and behavioral amyotrophic lateral sclerosis screen - a pilot study. Cesk Slov Neurol N. 2018;81(2):208-212. doi:10.14735/amcsnn2018208

54. Ahn S, Kim S, Kim J, et al. Frontal assessment battery to evaluate frontal lobe dysfunction in ALS patients. Can J Neurol Sci. 2011;38 (2):242-246. doi:10.1017/S0317167100011409

55. Ohta Y, Sato K, Takemoto M, et al. Behavioral and affective features of amyotrophic lateral sclerosis patients. $J$ Neurol Sci. 2017;381:119-125. doi:10.1016/j.jns.2017.08.024

56. Oskarsson B, Quan D, Rollins Y, Neville H, Ringel S, Arciniegas D. Using the Frontal assessment battery to identify executive function impairments in amyotrophic lateral sclerosis: A preliminary experience. Amyotroph Lateral Scler Frontotemporal Degener. 2010;11(12):244-247. doi:10.3109/17482960903059588

57. Barulli M, Fontana A, Panza F, et al. Frontal assessment battery for detecting executive dysfunction in amyotrophic lateral sclerosis without dementia: a retrospective observational study. BMJ Open. 2015;5:9. doi:10.1136/bmjopen-2014-007069 
58. Osborne R, Sekhon R, Johnston W, Kalra S. Screening for frontal lobe and general cognitive impairment in patients with amyotrophic lateral sclerosis. J Neurol Sci. 2014;336(12):191-196. doi:10.1016/j. jns.2013.10.038

59. Flaherty-Craig C, Brothers A, Yang C, Svoboda R, Simmons Z. Declines in problem solving and anosognosia in amyotrophic lateral sclerosis: application of Guilford's structure of intellect theory. Cog Behav Neurol. 2011;24(2):26-34. doi:10.1097/WNN.0b013e31821 38454

60. Christodoulou G, Gennings C, Hupf J, et al. Telephone based cognitive-behavioral screening for frontotemporal changes in patients with amyotrophic lateral sclerosis (ALS). Amyotroph Lateral Scler Frontotemporal Degener. 2016;17(78):482-488. doi:10.3109/ 21678421.2016.1173703

61. Murphy J, Ahmed F, Lomen-Hoerth C. The UCSF screening exam effectively screens cognitive and behavioral impairment in patients with ALS. Amyotroph Lateral Scler Frontotemporal Degener. 2015;16(12):24-30. doi:10.3109/21678421.2014.960873

62. Gillingham S, Yunusova Y, Ganda A, et al. Assessing cognitive functioning in ALS: A focus on frontal lobe processes. Amyotroph Lateral Scler Frontotemporal Degener. 2017;18(34):182-192. doi:10.1080/21678421.2016.1248977

63. Gordon PH, Wang Y, Doorish C, et al. A screening assessment of cognitive impairment in patients with ALS. Amyotrophic Lateral Sclerosis. 2007;8:362-365. doi:10.1080/17482960701500817

64. Lillo P, Savage S, Mioshi E, Kiernan M, Hodges J. Amyotrophic lateral sclerosis and frontotemporal dementia: A behavioural and cognitive continuum. Amyotroph Lateral Scler. 2012;13(1):102-109. doi:10.3109/17482968.2011.639376

65. Nidos A, Kasselimis D, Simos P, et al. Frontotemporal dysfunction in amyotrophic lateral sclerosis: A discriminant function analysis. Neurodegener Dis. 2016;16(34):140-146. doi:10.1159/000381186

66. Tsermentseli S, Leigh P, Taylor L, Radunovic A, Catani M, Goldstein L. Syntactic processing as a marker for cognitive impairment in amyotrophic lateral sclerosis. Amyotroph Lateral Scler Frontotemporal Degener. 2015;17(12):69-76. doi:10.3109/ 21678421.2015.1071397
67. Heidler-Gary J, Hillis A. Distinctions between the dementia in amyotrophic lateral sclerosis with frontotemporal dementia and the dementia of Alzheimer's disease. Amyotroph Lateral Scler. 2007;8 (5):276-282. doi:10.1080/17482960701381911

68. Baylor C, Yorkston K, Eadie T, Kim J, Chung H, Amtmann D. The Communicative participation item bank (CPIB): item bank calibration and development of a disorder-generic short form. J Speech Lang Hear Res. 2013;56(4):1190-1208. doi:10.1044/1092-4388(2012/12-0140)

69. Gallassi R, Montagna P, Ciardulli C, Lorusso S, Mussuto V, Stracciari A. Cognitive impairment in motor neuron disease. Acta Neurol Scand. 1985;71(6):480-484. doi:10.1111/j.1600-0404.1985. tb03231.x

70. Altman D. Practical Statistics for Medical Research. London: Chapman and Hall; 1991.

71. Simon N, Goldstein L. Screening for cognitive and behavioral change in amyotrophic lateral sclerosis/motor neuron disease: a systematic review of validated screening methods. Amyotroph Lateral Scler Frontotemporal Degener. 2018;20:1-11. doi:10.1080/21678421.2018.1530264

72. Crockford CJ, Kleynhans M, Wilton E, et al. ECAS A-B-C: alternate forms of the edinburgh cognitive and behavioural ALS screen. Amyotroph Lat Scl Fr. 2018;19(12):57-64.

73. Baron-Cohen S, Wheelwright S, Hill J, Raste Y, The IP. Reading in the mind in the eyes" test revised version: a study with normal adults, and adults with asperger syndrome or high-functioning autism. J Child Psychol Psychiatry. 2001;42:241-251. doi:10.1111/14697610.00715

74. Taule T, AS. M, Renså M, Aßmus J, Tysnes O, Rekand T. Edinburgh cognitive and behavioural amyotrophic lateral sclerosis screen (ECAS) in Norway: protocol for validation and a prospective cohort study. Contemp Clin Trials Commun. 2019;14.

\section{Publish your work in this journal}

Patient Related Outcome Measures is an international, peer-reviewed, open access journal focusing on treatment outcomes specifically relevant to patients. All aspects of patient care are addressed within the journal and practitioners from all disciplines are invited to submit their work as well as healthcare researchers and patient support groups.
The manuscript management system is completely online and includes a very quick and fair peer-review system. Visit http://www. dovepress.com/testimonials.php to read real quotes from published authors. 